\title{
ERp29 downregulation enhances lung adenocarcinoma cell chemosensitivity to gemcitabine by upregulating HSP27 phosphorylation
}

\author{
WU YE ${ }^{1}$, ZHIJUN LI ${ }^{1}$, TINGYU TANG ${ }^{1}$, JIANZONG DU ${ }^{1}$, XIAOXI ZHOU ${ }^{1}$, \\ HAIYAN WU ${ }^{1}$, XUEFANG LI $^{2}$ and GUANGYUE QIN ${ }^{1}$ \\ Departments of ${ }^{1}$ Respiratory Diseases and ${ }^{2}$ Cardiovascular Medicine, \\ Zhejiang Hospital, Hangzhou, Zhejiang 310013, P.R. China
}

Received May 1, 2018; Accepted October 26, 2018

DOI: $10.3892 /$ etm.2018.7040

\begin{abstract}
The aim of the current study was to assess the underlying mechanism of endoplasmic reticulum protein 29 (ERp29) in lung adenocarcinoma chemosensitivity to gemcitabine. Western blot analysis was performed to detect ERp29 expression following lung adenocarcinoma cell treatment with gemcitabine. The effects of gemcitabine in combination with ERp29 siRNA on cell apoptosis, cell cycle and heat shock protein 27 (HSP27) expression were assessed. The results demonstrated that ERp29 expression was increased on exposure to gemcitabine. The apoptotic rate of lung adenocarcinoma cells were also increased following gemcitabine treatment and the combined application of gemcitabine and ERp29 siRNA synergistically increased apoptotic rates further. It was also revealed that gemcitabine and ERp29 siRNA synergistically increased the ratio of phosphorylated to total HSP27 protein. In addition, downregulation of HSP27 significantly reduced lung adenocarcinoma chemosensitivity to gemcitabine. These data indicate that ERp29 affects lung adenocarcinoma cell chemosensitivity to gemcitabine by regulating phosphorylated HSP27. ERp29 is a novel target, which may be used to enhance the therapeutic effect of lung adenocarcinoma treatment with gemcitabine.
\end{abstract}

\section{Introduction}

As the most common histologic subtype of lung cancer, lung adenocarcinoma is the leading cause of cancer mortality worldwide $(1,2)$. Molecular targeted drugs have been demonstrated to improve quality of life and therapeutic effects in patients with lung adenocarcinoma whose tumors exhibit driver oncogenes, including epidermal growth factor receptor

Correspondence to: Professor Guangyue Qin, Department of Respiratory Diseases, Zhejiang Hospital, 12 Lingyin Road, Hangzhou, Zhejiang 310013, P.R. China

E-mail: hzqgy@126.com

Key words: endoplasmic reticulum protein 29, lung adenocarcinoma, gemcitabine, chemosensitivity, heat shock protein 27 mutations, anaplastic lymphoma kinase gene rearrangements or ROS proto-oncogene 1 gene fusion $(2,3)$. However, most lung adenocarcinomas lack an identifiable activated oncogene and remain to be treated with conventional chemotherapy $(2,3)$.

Endoplasmic reticulum protein 29 (ERp29), a putative chaperone protein, is located in the endoplasmic reticulum (4). Structurally, ERp29 consists of an N-terminal domain, a flexible loop and a C-terminal domain (4). ERp29 is upregulated on exposure to radiation, homocysteine or dopamine (5-7). ERp29 is abnormally expressed in several types of tumors, including breast cancer, colorectal cancer, basal skin carcinoma and gallbladder adenocarcinoma (8-11). Furthermore, ERp29 expression is associated with the pathological grade, TNM stage, lymph node metastasis, recurrence and prognosis of patients with cancer (8-11). It has also been revealed that ERp29 overexpression enhances breast cancer cell chemoresistance to doxorubicin and nasopharyngeal carcinoma cell radioresistance $(9,12)$.

A previous study has revealed that ERp29 is significantly overexpressed in 75 patients with lung adenocarcinoma and of ERp29 inhibition enhances gemcitabine chemosensitivity (13). Therefore, treatment with gemcitabine in combination with ERp29 expression inhibition may promote therapeutic effects in lung adenocarcinoma. However, underlying mechanisms of this action are yet to be elucidated. It has been revealed that ERp29 is involved in the regulation of heat shock protein 27 (HSP) $(5,14)$. In addition, as a small HSP, HSP27 is associated with gemcitabine chemotherapeutic sensitivity $(15,16)$. Therefore, the current study hypothesized that ERp29 may affect the chemosensitivity of lung cancer cells to gemcitabine by regulating HSP27. In the present study, ERp29 and HSP27 expression was assessed following lung adenocarcinoma cell treatment with gemcitabine. Furthermore, effects of combined treatment with gemcitabine and ERp29 small interfering (si)RNA on cell apoptosis, cell cycle and HSP27 expression were examined in the present study.

\section{Materials and methods}

Cell lines and cell culture. A549 and SPC-A1 human lung adenocarcinoma cells (Type Culture Collection of the Chinese Academy of Science, Shanghai, China) were cultured in 
RPMI-1640 medium supplemented with $10 \%$ fetal bovine serum (Gibco; Thermo Fisher Scientific, Inc., Waltham, MA, USA) and maintained at $37^{\circ} \mathrm{C}$ in a $5 \% \mathrm{CO}_{2}$-humidified incubator.

Western blot analysis. Total protein was extracted from lung adenocarcinoma cells using radio immunoprecipitation assay buffer (Beyotime Institute of Biotechnology, Haimen, China). Total protein was quantified using a bicinchoninic acid assay and 30-60 $\mu \mathrm{g}$ protein/lane was separated via SDS-PAGE on a $12 \%$ gel using a mini-gel apparatus (Bio-Rad Laboratories, Inc., Hercules, CA, USA). The separated proteins were subsequently transferred onto polyvinylidene difluoride membranes and for $1.5 \mathrm{~h}$ at room temperature with $5 \%$ non-fat dry milk in Tris-buffered saline with Tween-20 (TBST). The membranes were incubated with primary antibodies against ERp29 (1:500; cat. no. ab176573; Abcam, Cambridge, UK), HSP27 (1:1,000; cat. no. 2402), phosphorylated (p)-HSP27 (Ser82; 1:1,000; cat. no. 9709) (both from Cell Signaling Technology, Inc., Danvers, MA, USA) and $\alpha$-tubulin antibodies (1:3,000; cat. no. T5168; Sigma-Aldrich; Merck KGaA, Darmstadt, Germany) overnight at $4^{\circ} \mathrm{C}$. Membranes were washed with TBST. Following primary incubation, membranes were incubated with horseradish peroxidase-conjugated anti-rabbit $\operatorname{IgG}(1: 1,000$; cat. no. 7074) and anti-mouse $\operatorname{IgG}(1: 1,000$; cat. no. 7076; both from Cell Signaling Technology, Inc.) secondary antibodies for $1 \mathrm{~h}$ at room temperature. Protein bands were visualized using an enhanced chemiluminescence kit (Beyotime Institute of Biotechnology). Protein expression was quantified using ImageJ software (National Institutes of Health, Bethesda, MD, USA). Following treatment with various doses $(0.5,5$ and $50 \mu \mathrm{M}$ ) of gemcitabine (Selleck Chemicals, Houston, TX, USA) for 24 h, ERp29 expression in lung adenocarcinoma cells was detected. HSP27 and p-HSP27 expression levels were detected following treatment with $5 \mu \mathrm{M}$ gemcitabine for 4, 8 and $24 \mathrm{~h}$ in A549 and SPC-A1 cells.

siRNA transfection. ERp29 siRNA, HSP27 siRNA and scrambled siRNA were designed and synthesized by Shanghai GenePharma Co., Ltd. (Shanghai, China). The following gene-specific siRNA duplexes: ERP29-siRNA sense, 5'-GUG AGUCCCUUGUGGAAUATT-3' and antisense, 5'-UAUUCC ACAAGGGACUCACTT-3' and HSP27-siRNA sense, 5'-ACC UGUGUGUUCUUUUGAUTT-3' and antisense, 5'-AUCAAA AGAACACACAGGUTT-3'. Cells were transfected with $40 \mathrm{nM}$ siRNA using Lipofectamine ${ }^{\circledR} 3000$ (Invitrogen; Thermo Fisher Scientific, Inc.), according to the manufacturer's protocol. Thereafter, cells were harvested for western blot analysis following 72-h transfection.

Detection of apoptosis. Cell apoptosis was analyzed using the Annexin V-fluorescein isothiocyanate (FITC) Apoptosis Detection kit (BD Biosciences, Franklin Lakes, NJ, USA). A total of $1 \times 10^{5}$ cells were collected by centrifugation at $170 \mathrm{xg}$ for $5 \mathrm{~min}$ at room temperature. The cells were suspended in $100 \mu \mathrm{l}$ of binding buffer and subsequently stained with $5 \mu \mathrm{l}$ Annexin V-FITC and $5 \mu 1$ propidium iodide (PI) in the dark for $15 \mathrm{~min}$ at room temperature. Apoptotic cells were analyzed using a BD FACSCalibur flow cytometer (BD Biosciences) and FlowJo software (version 7.6.1; TreeStar, Inc., Ashland,
OR, USA). Apoptotic cells were defined as Annexin V-positive cells.

Cell cycle assay. A cell cycle kit (Beyotime Institute of Biotechnology) was used to determine the percentage of cells in $G_{1}, S$ and $G_{2}$ phases of the cell cycle. Lung adenocarcinoma cells were divided into 4 groups: The control group (transfected with control siRNA), the ERp29 siRNA group (transfected with ERp29 siRNA), the gemcitabine group (transfected with control siRNA and treated with gemcitabine) and the combination group (transfected with ERp29 siRNA and treated with gemcitabine). Single-cell suspensions were fixed using $70 \%$ ethanol for $24 \mathrm{~h}$ at $4^{\circ} \mathrm{C}$. Cells were subsequently washed with phosphate buffered saline, stained with $0.5 \mathrm{ml}$ PI for $30 \mathrm{~min}$ at room temperature and analyzed using a BD FACS Calibur flow cytometer and Cell Quest software (version 5.1; BD Biosciences).

Cytotoxicity assay. Gemcitabine cytotoxicity was quantified using a Cell Counting kit-8 (CCK-8) assay (7Sea Biotech, Shanghai, China). Cells were seeded in 96-well plates at a density of $3 \times 10^{3}$ A549 cells/well or $3.5 \times 10^{3}$ SPC-A1 cells/well. Following 48 -h treatment with gemcitabine $(0.6 \mu \mathrm{M}$ for A549 or $6 \mu \mathrm{M}$ for SPC-A1 cells) at room temperature, cells were incubated with $10 \mu \mathrm{l} \mathrm{CCK}-8$ solution for $1 \mathrm{~h}$ at room temperature. The optical density (OD) was measured at $450 \mathrm{~nm}$ using a Multiskan Go Microplate spectrophotometer (Thermo Fisher Scientific, Inc.). The cell growth inhibition rate of gemcitabine was calculated as follows: $\left(1-\mathrm{OD}_{450}\right.$ of treated cells/OD ${ }_{450}$ of untreated cells) x100\%.

Statistical analysis. All statistical analyses were performed using SPSS 13.0 (SPSS, Inc., Chicago, IL, USA). Data are presented as the mean \pm standard error of the mean. Differences between two groups were assessed using Student's t-test. Multiple comparisons between groups were analyzed using one-way analysis of variance followed by Fisher's least significant difference post-hoc tests. $\mathrm{P}<0.05$ was considered to indicate a statistically significant difference.

\section{Results}

Exposure of lung adenocarcinoma cells to gemcitabine increases ERp29 expression. As presented in Fig. 1, ERp29 expression was significantly increased on exposure to gemcitabine $(\mathrm{P}<0.05)$. Erp29 expression was significantly increased at $50 \mu \mathrm{M}$ in $\mathrm{A} 459$ cells and $5 \mu \mathrm{M}$ in SPC-A1 cells, respectively.

Effects of gemcitabine and ERp29 siRNA on lung adenocarcinoma cell apoptosis. Following treatment with $20 \mu \mathrm{M}$ gemcitabine, the apoptotic rate of A549 cells increased from $6.43 \pm 0.55$ in the control group to $20.90 \pm 2.83 \%$ in the control $+20 \mu \mathrm{M}$ gemcitabine group (Fig. 2). Treatment with gemcitabine in combination with ERp29 siRNA significantly increased the apoptotic rate to $30.80 \pm 1.41 \%$ compared with gemcitabine treatment alone (Fig. 2). Following treatment with $50 \mu \mathrm{M}$ gemcitabine, the SPC-A1 cell apoptotic rate was increased from $6.10 \pm 1.12$ in the control group to $19.82 \pm 1.76 \%$ in the control $+50 \mu \mathrm{M}$ gemcitabine group. Treatment with 


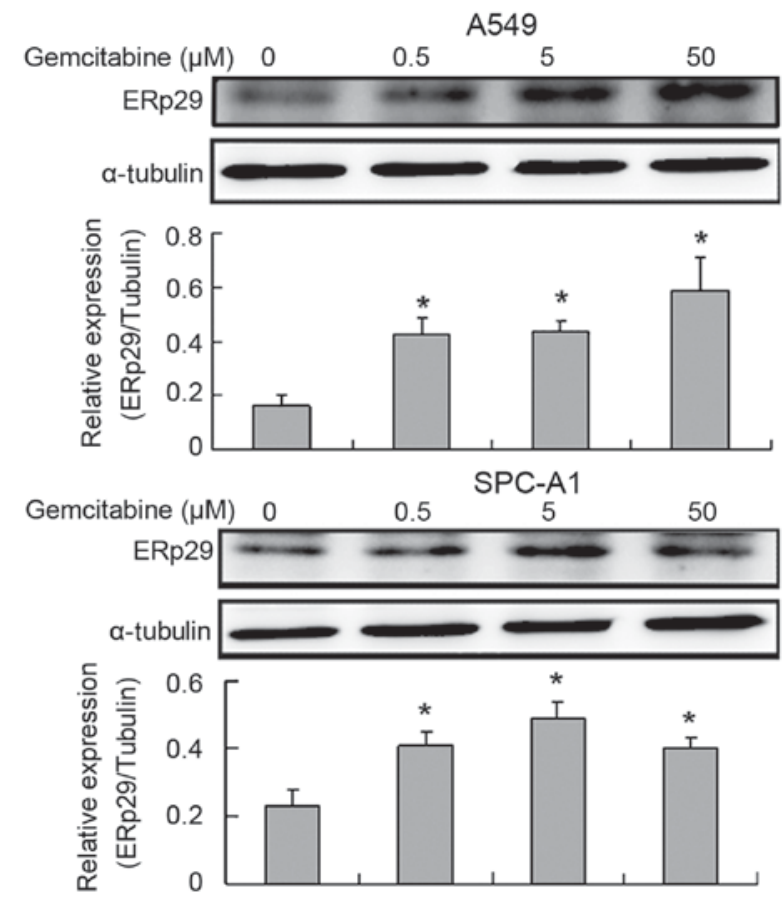

Figure 1. ERp29 expression increases in A549 and SPC-A1 cells exposed to gemcitabine. ERp29 protein expression was assessed by western blot and normalized to $\alpha$-tubulin. ERp29 expression increased when exposed to gemcitabine. ${ }^{*} \mathrm{P}<0.05$ vs. the $0 \mu \mathrm{M}$ gemcitabine group. ERp29, endoplasmic reticulum protein 29 . gemcitabine in combination with ERp29 siRNA significantly increased the apoptotic rate to $27.53 \pm 1.11 \%$ compared with gemcitabine treatment alone (Fig. 2). The apoptotic rate of A549 and SPC-A1 cells in the Si-control and ERp29 siRNA group were not significantly different.

Effects of gemcitabine and ERp29 siRNA on the cell cycle of lung adenocarcinoma cells. Lung adenocarcinoma cells in the gemcitabine and combination groups were treated with $20 \mu \mathrm{M}$ gemcitabine. As presented in Fig. 3, the percentage of gemcitabine-treated cells in the $\mathrm{S}$ phase was significantly increased compared with untreated cells in the $\mathrm{S}$ phase in the A549 Si-control group (31.80 2.81 vs. $19.12 \pm 1.00 \%$; $\mathrm{P}<0.05)$. Similar results were obtained in SPC-A1 cells $(29.12 \pm 1.84$ vs. $19.78 \pm 0.39 \%$; $\mathrm{P}<0.05)$. The percentage of gemcitabine-treated cells in the $\mathrm{S}$ phase was increased compared with untreated cells in the S phase in the A549 Si-ERp29 group and similar results were obtained in SPC-A1 cells. There were no significant differences in the level of $\mathrm{G}_{1}$ and $\mathrm{G}_{2}$ cell cycle arrest observed in the ERp29 siRNA or Si-control groups.

Effects of ERp29 siRNA on HSP27 expression in lung adenocarcinoma cells. Lung adenocarcinoma cell lines were transfected with ERp29 or control siRNA. At $72 \mathrm{~h}$ following transfection, ERp29, HSP27 and p-HSP27 levels were detected
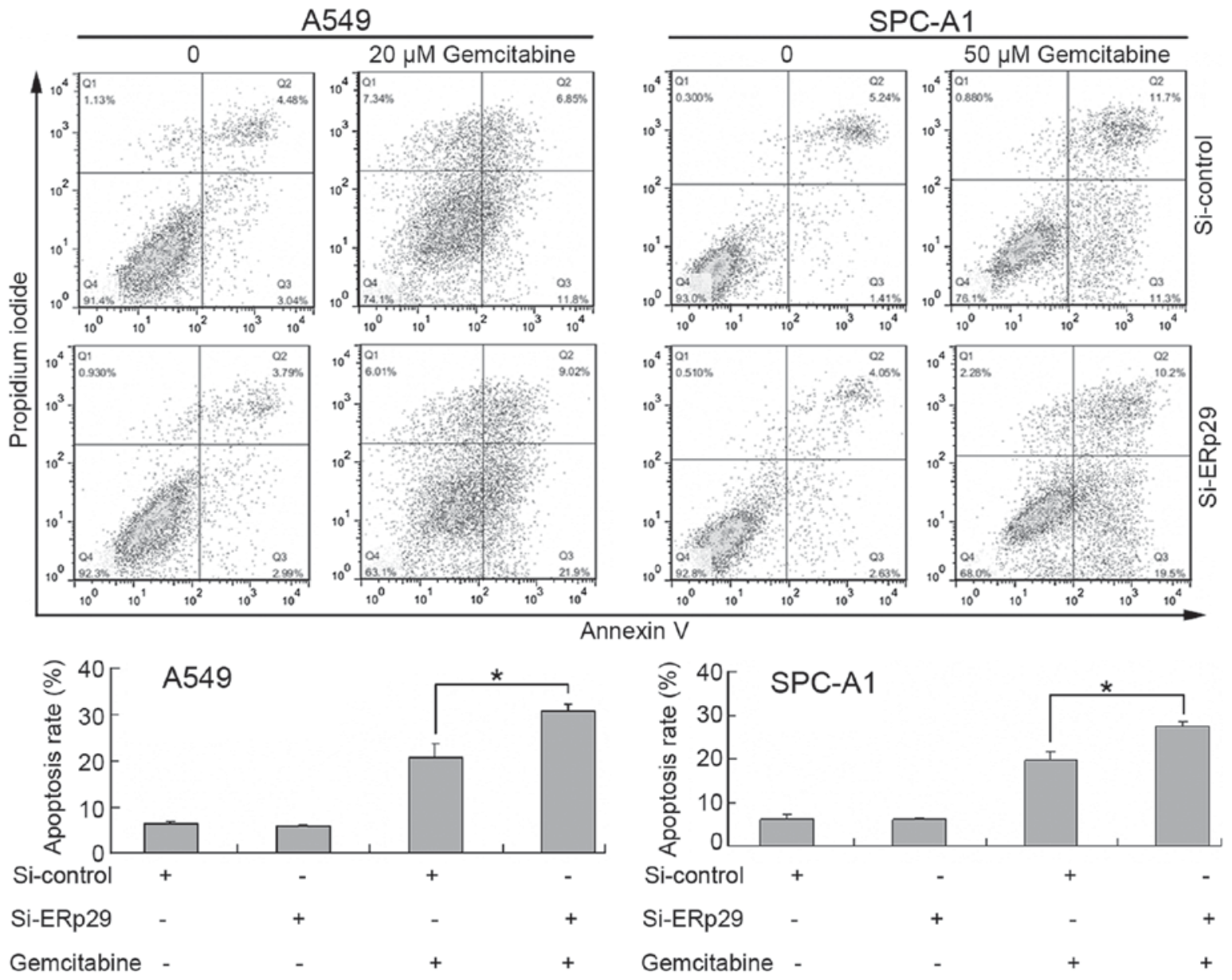

Figure 2. Combined gemcitabine and ERp29 siRNA treatment increases apoptosis in lung adenocarcinoma cells. Flow cytometry was performed to analyze apoptosis rates. ${ }^{*} \mathrm{P}<0.05$. $\mathrm{Si}$, small interfering RNA; ERp29, endoplasmic reticulum protein 29. 
A

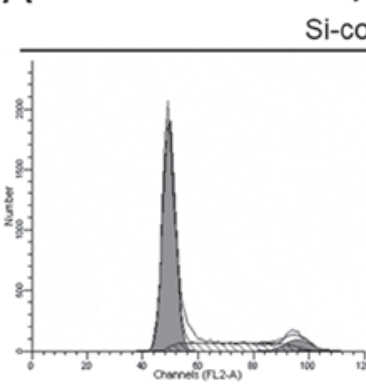

0

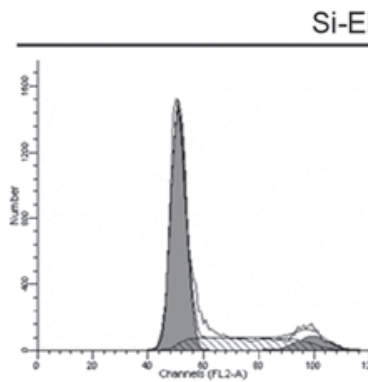

0

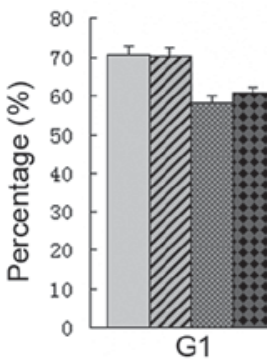

A549

Si-control

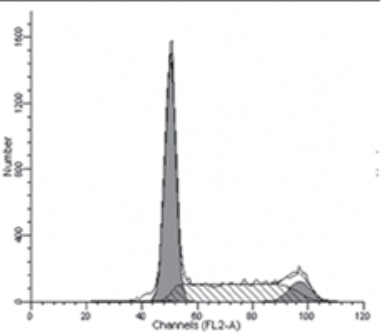

$20 \mu \mathrm{M}$ Gemcitabine

-ERp29

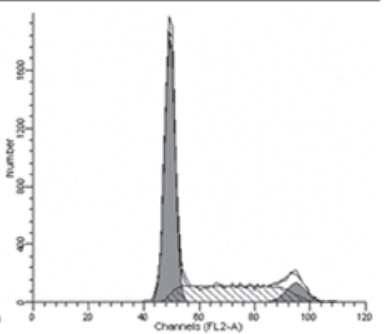

$20 \mu \mathrm{M}$ Gemcitabine

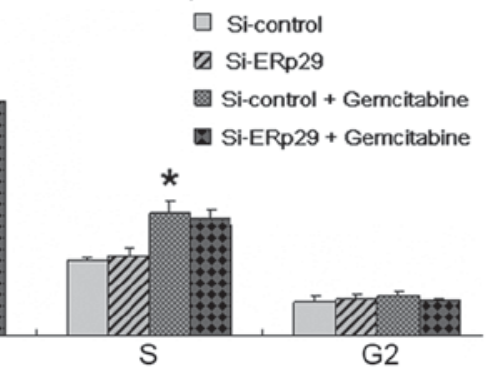

B

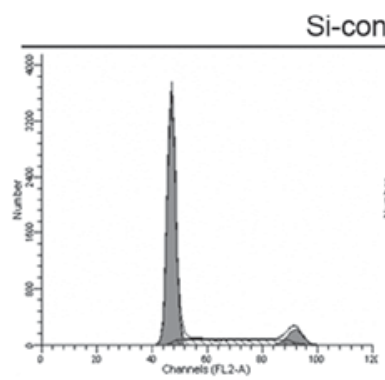

0

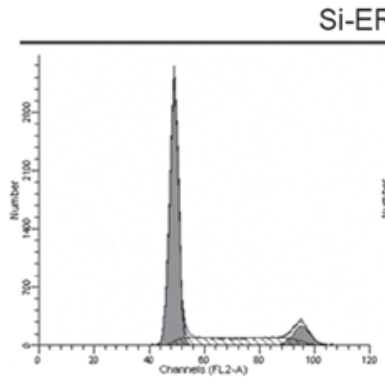

0

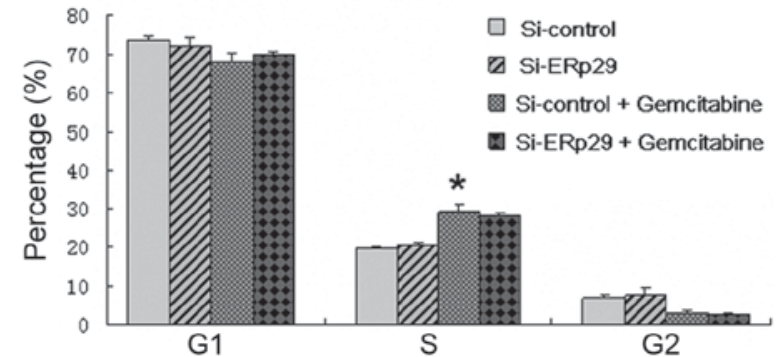

Figure 3. Gemcitabine changes the cell cycle of lung adenocarcinoma cells. The cell cycle of treated (A) A549 and (B) SPC-A1 cells was determined by flow cytometry. The percentage of cells in the $\mathrm{S}$ phase of the gemcitabine group was significantly higher than that of the control group. There were no significant differences in the cell cycles of the ERp29 siRNA and Si-control group, and in combination and gemcitabine group. Si, small interfering RNA; ERp29, endoplasmic reticulum protein $29 .{ }^{*} \mathrm{P}<0.05$ vs. $0 \mu \mathrm{M}$ group.

using western blotting. The downregulation of ERp29 significantly increased the ratio of p-HSP27 to total HSP27 (P<0.05; Fig. 4).

Effects of gemcitabine on HSP27 expression in lung adenocarcinoma cells. Phosphorylation of HSP27 was significantly increased in gemcitabine-treated cells compared with the $0 \mathrm{~h}$ group $(\mathrm{P}<0.05$; Fig. 5). However, gemcitabine-induced HSP27 phosphorylation was not found to be time-dependent.

Effects of gemcitabine in combination with ERp29 siRNA on HSP27 expression. Lung adenocarcinoma cells in the gemcitabine and combination groups were treated with $5 \mu \mathrm{M}$ gemcitabine. Phosphorylation of HSP27 in the combination group was significantly higher compared with the other three groups $(\mathrm{P}<0.05$; Fig. 6$)$.

Effects of HSP27 siRNA on lung adenocarcinoma cell chemosensitivity to gemcitabine. Lung adenocarcinoma cells were transfected with HSP27 siRNA or control siRNA. As presented in Fig. 7, HSP27 expression was effectively reduced in A549 and SPC-A1 cells transfected with HSP27 siRNA compared with the control RNA. The downregulation of HSP27 expression in A549 cells significantly decreased the cell growth inhibition rate of gemcitabine compared with the control $(37.79 \pm 2.99$ vs. $55.63 \pm 4.28 \%$; $\mathrm{P}<0.05)$. Furthermore, the cell growth inhibition rate of gemcitabine in HSP27-inhibiting SPC-A1 cells was significantly lower than that of the control $(54.82 \pm 3.15$ vs. $64.80 \pm 0.62 \%$; $\mathrm{P}<0.05)$.

\section{Discussion}

The present study investigated the role of ERp29 in lung adenocarcinoma cell chemosensitivity to gemcitabine. The results demonstrated that ERp29 expression in A549 and SPC-A1 cells was increased on exposure to gemcitabine. Furthermore, ERp29 downregulation significantly increased apoptosis induced by gemcitabine. It was further demonstrated that gemcitabine and ERp29 siRNA synergistically increased HSP27 phosphorylation and HSP27 downregulation significantly reduced chemosensitivity to gemcitabine.

A previous study revealed that ERp29 was overexpressed in patients with lung adenocarcinoma and ERp29 inhibition significantly enhanced the cytotoxic effects of gemcitabine (13). However, the underlying mechanism of this effect is poorly understood. Zhang et al (17) demonstrated that 


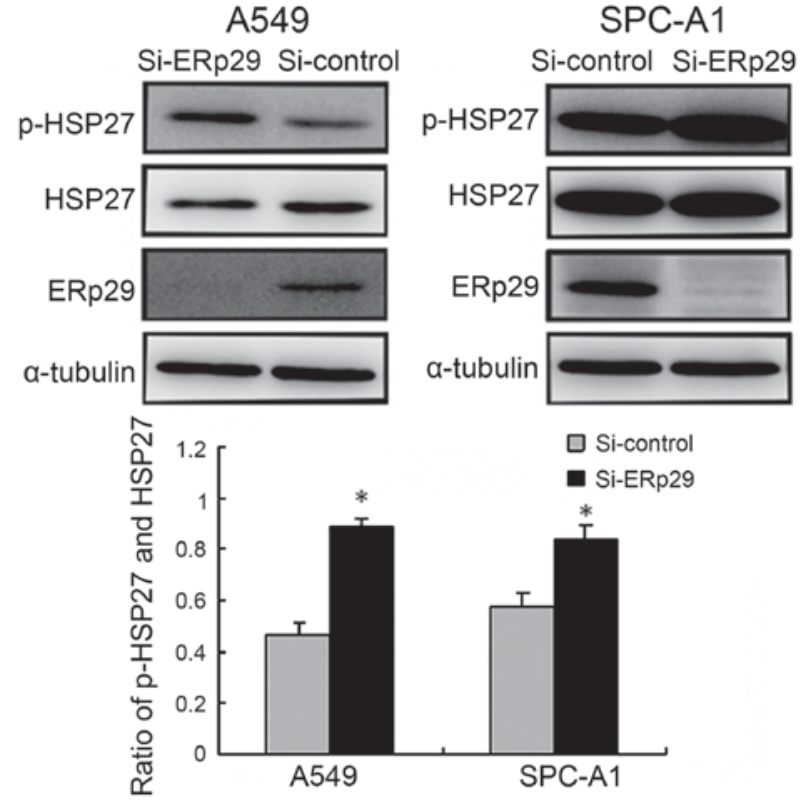

Figure 4. ERp29 downregulation increases HSP27 phosphorylation in lung adenocarcinoma cells. ERp29 siRNA treatment significantly increased HSP27 phosphorylation as determined by western blot analysis. ${ }^{*} \mathrm{P}<0.05$ vs. Si-control group. ERp29, endoplasmic reticulum protein 29; $\mathrm{Si}$, small interfering RNA; HSP27, heat shock protein 27.

ERp29 overexpression in cortical neurons following axotomy prevents the reduction of neurite length and neuron number, and protects from apoptosis. Furthermore, a previous study revealed that ERp29 is upregulated on exposure to radiation and ERp29 expression protects cells from damage caused by ionizing radiation (5). In the present study, lung adenocarcinoma cells were exposed to gemcitabine and ERp29 expression was significantly increased. This may be due to certain stimuli in the tumor microenvironment causing ERp29 upregulation, which may serve a cytoprotective role $(9,17)$. In the current study, lung cancer cells were treated with gemcitabine for $24 \mathrm{~h}$ and the analysis of time-dependent effects of gemcitabine on ERp29 expression requires further examination.

Cell apoptosis is one of the main mechanisms of antineoplastic activity employed by chemotherapeutic agents (18). Gemcitabine exerts cytotoxic effects primarily by inducing tumor cell apoptosis via blockage of DNA synthesis and repair $(19,20)$. In the present study, A549 and SPC-A1 apoptotic rates were increased following treatment with gemcitabine and the combined application of gemcitabine and ERp29 siRNA synergistically increased apoptotic rates further. Zhang and Putti (9) demonstrated that ERp29 downregulation significantly increased doxorubicin-induced apoptosis and ERp29 overexpression decreased cell apoptosis. Additionally, ERp29 inhibition enhances cell apoptosis induced by ionizing radiation and cigarette smoke extract via caspase- 3 and -7 expression $(5,12,21,22)$.

Gemcitabine is a cell cycle-specific drug that acts primarily in the S phase $(23,24)$. In the present study, A549 cells were treated with $20 \mu \mathrm{M}$ gemcitabine for $48 \mathrm{~h}$. The percentage of cells in the $\mathrm{S}$ phase of the gemcitabine group was significantly higher than that of the control group. However, the combined application of gemcitabine and ERp29 siRNA did not alter the effect of gemcitabine. Few studies have assessed the role of

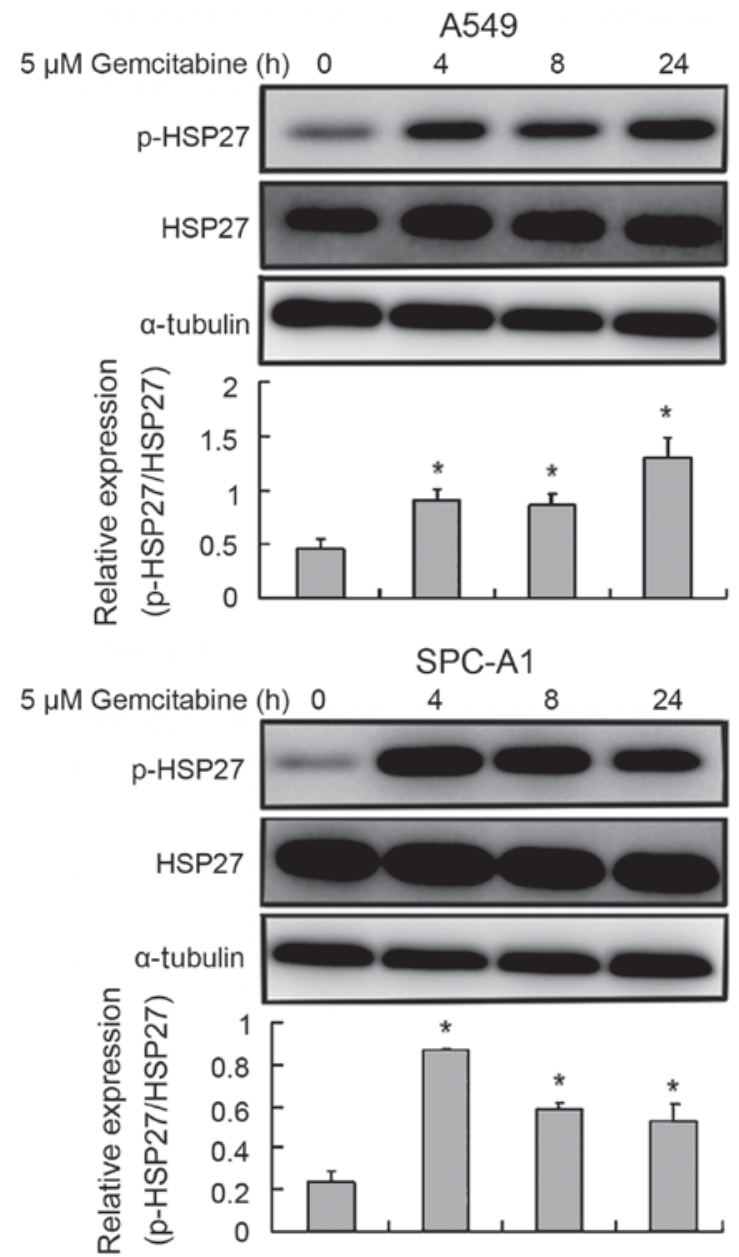

Figure 5. Gemcitabine treatment increases HSP27 phosphorylation in lung adenocarcinoma cells over time. Western blot analysis was performed to assess HSP27 phosphorylation in A549 and SPC-A1 cells over time. ${ }^{*} \mathrm{P}<0.05$ vs. the $0 \mathrm{~h}$ group. HSP27, heat shock protein 27; p, phosphorylated.

ERp29 in cell cycle control and the exact mechanism requires further investigation $(5,9)$.

HSPs can be divided into 5 families: HSP110, HSP90, HSP70, HSP60 and small HSP (25). HSP27, a small HSP with a molecular weight of $27 \mathrm{kDa}$, consists of 205 amino acid residues (26). The C-terminus of HSP27 contains a highly conserved $\alpha$-crystallin domain and the $\mathrm{N}$-terminus comprises a WDPF domain and a PSRLFDQXFGEXLL sequence (26). In the present study, ERp29 downregulation and treatment with gemcitabine combined with ERp29 siRNA were revealed to significantly increase HSP27 phosphorylation. Nakashima et al (27) have revealed that HSP27 phosphorylation is increased following pancreatic cancer cell treatment with gemcitabine. Similar results were observed in the current study. The phosphorylation of HSP27 is primarily catalyzed by mitogen-activated protein kinase-activated protein kinase (MAPKAPK)-2, MAPKAPK-3 and MAPKAPK-5, protein kinase (PK) A, PKB and PKC $(28,29)$. Furthermore, MAPKAPK2 activation enhances damaging effects of gemcitabine on DNA and inhibits DNA repair (30). However, the association between ERp29 and HSP27 requires to be further elucidated.

In the current study, HSP27 downregulation significantly reduced chemosensitivity to gemcitabine in A549 

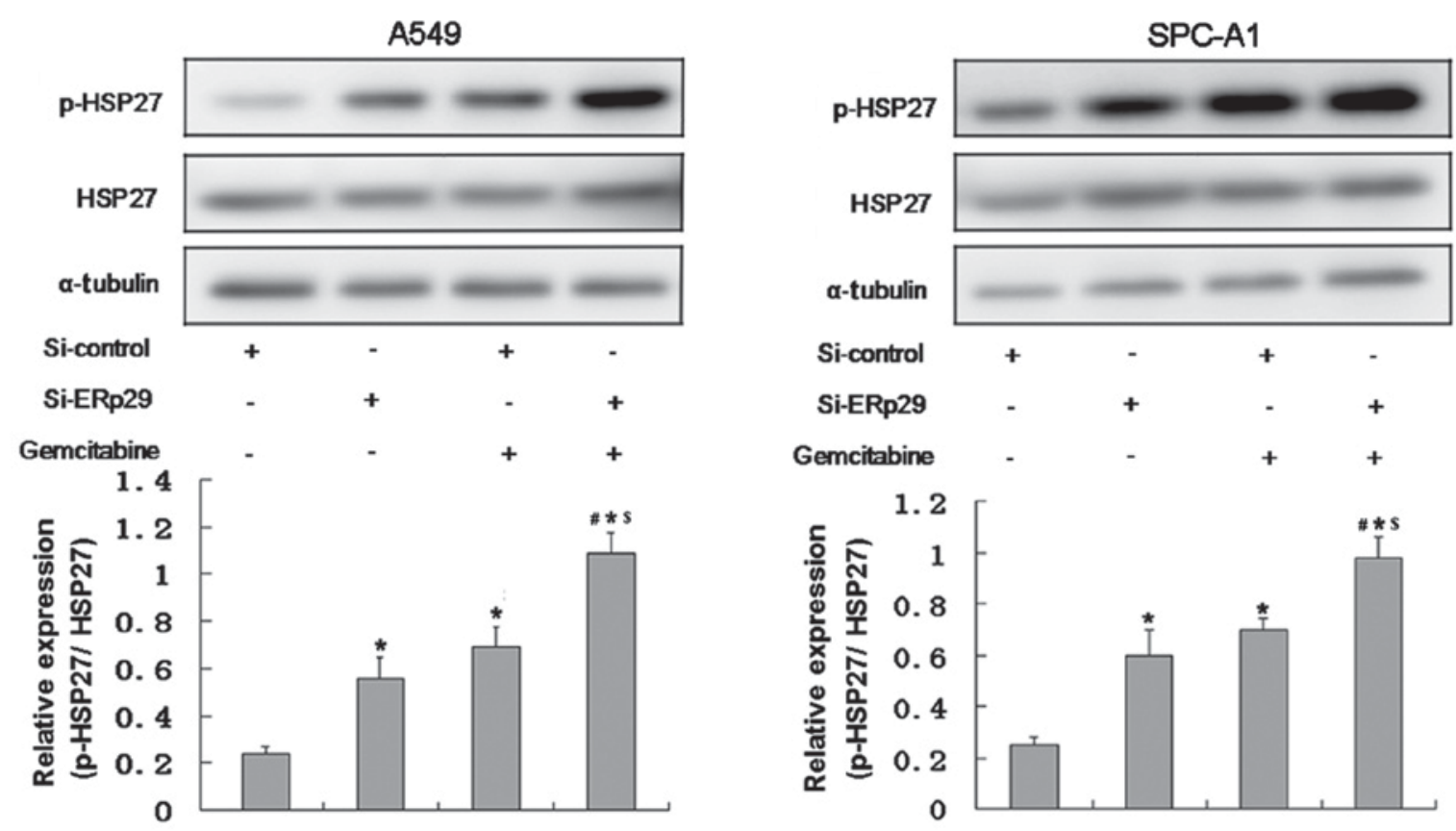

Figure 6. Combined gemcitabine and ERp29 siRNA treatment increases HSP27 phosphorylation. Gemcitabine and ERp29 siRNA synergistically increased HSP27 phosphorylation as determined by western blot analysis. " $\mathrm{P}<0.05$ vs. Si-control; ${ }^{\prime} \mathrm{P}<0.05$ vs. Si-ERp29; and ${ }^{\text {S }} \mathrm{P}<0.05$ vs. Si-control $+\mathrm{Gemcitabine}$. ERp29,endoplasmic reticulum protein 29; Si, small interfering RNA; HSP27, heat shock protein 27; p, phosphorylated.
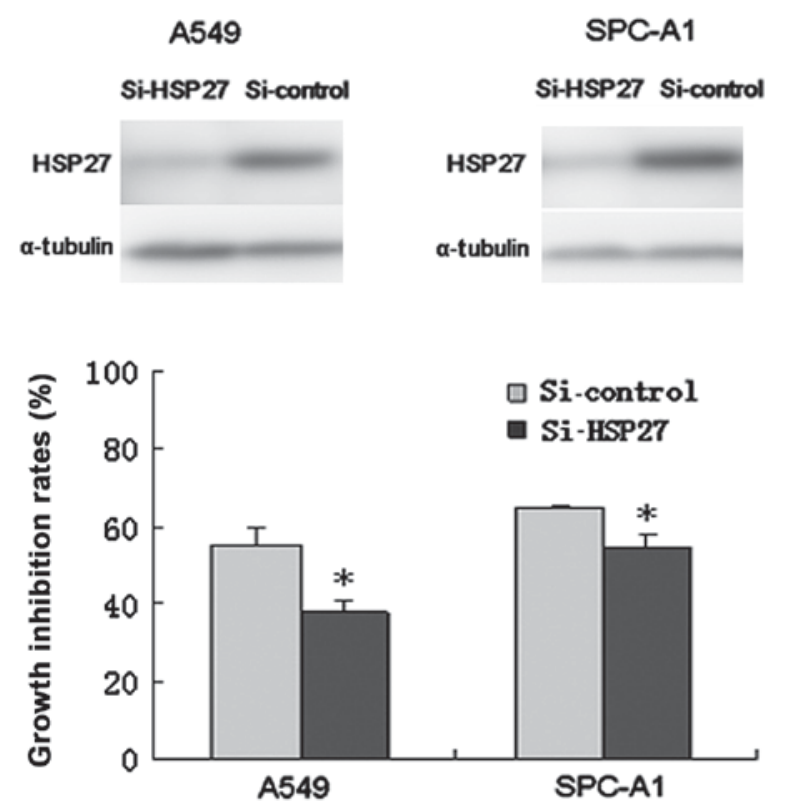

Figure 7.HSP27 downregulation reduces lung adenocarcinoma cell chemosensitivity to gemcitabine. HSP27 siRNA treatment significantly reduced HSP27 expression as determined by western blot and further decreased cell growth inhibition rates determined using cell counting kit- 8 assays. ${ }^{*} \mathrm{P}<0.05$ vs. the Si-control group. HSP27, heat shock protein 27; Si, small interfering RNA.

and SPC-A1 cells. This finding was consistent with a report by Schäfer et al (15), who revealed that HSP27 expression inhibition in AsPC-1 pancreatic cancer cells attenuated gemcitabine cytotoxicity. HSP27 downregulation has been demonstrated to inhibit apoptosis by regulating caspase-3, B-cell lymphoma/leukemia-2 (Bcl-2), Bcl-2 associated $\mathrm{X}$ protein and poly-ADP-ribose polymerase (PARP) $(31,32)$. Guo et al (16) revealed that the combination of gemcitabine and HSP27 overexpression synergistically increased apoptosis in pancreatic cancer cells and increased PARP expression and caspase- $-3,-8$ and -9 cleavage.

In summary, ERp29 expression was upregulated on exposure to gemcitabine and increased ERp29 expression protected lung adenocarcinoma cells from cytotoxic effects of gemcitabine. It was further revealed that ERp29 inhibition increases apoptotic rates induced by gemcitabine, which is one of the main mechanisms of its antitumor effect $(18,33)$. ERp29 may therefore affect lung cancer cell chemosensitivity to gemcitabine by regulating HSP27 phosphorylation. However, further studies, including in vivo research, are required to verify these results.

ERp29 is a novel target, inhibition of ERp29 expression may be used to enhance the therapeutic effect of lung adenocarcinoma treatment with gemcitabine.

\section{Acknowledgements}

Not applicable.

\section{Funding}

No funding was received.

\section{Availability of data and materials}

All datasets used and/or generated during the current study are available from the corresponding author on reasonable request.

\section{Authors' contributions}

WY and GQ designed the study. WY, ZL, TT and JD performed the experiment. XZ, HW and XL analyzed the data 
and prepared the manuscript. All authors read and approved the final manuscript.

\section{Ethics approval and consent to participate}

Not applicable.

\section{Patient consent for publication}

Not applicable.

\section{Competing interests}

The authors declare that they have no competing interests.

\section{References}

1. Bender E: Epidemiology: The dominant malignancy. Nature 513: S2-S3, 2014.

2. Cancer Genome Atlas Research Network: Author correction comprehensive molecular profiling of lung adenocarcinoma. Nature 559: E12, 2018.

3. Berge EM and Doebele RC: Targeted therapies in non-small cell lung cancer: Emerging oncogene targets following the success of epidermal growth factor receptor. Semin Oncol 41: 110-125, 2014.

4. Mkrtchian S and Sandalova T: ERp29, an unusual redox-inactive member of the thioredoxin family. Antioxid Redox Signal 8 325-337, 2006

5. Zhang B, Wang M, Yang Y, Wang Y, Pang X, Su Y, Wang J, Ai G and Zou Z: ERp29 is a radiation-responsive gene in IEC-6 cell. J Radiat Res 49: 587-596, 2008.

6. Hung YC, Wang PW, Pan TL, Bazylak G and Leu YL: Proteomic screening of antioxidant effects exhibited by radix salvia miltiorrhiza aqueous extract in cultured rat aortic smooth muscle cells under homocysteine treatment. J Ethnopharmacol 124: 463-474, 2009.

7. Dukes AA, Van Laar VS, Cascio M and Hastings TG: Changes in endoplasmic reticulum stress proteins and aldolase $\mathrm{A}$ in cells exposed to dopamine. J Neurochem 106: 333-346, 2008.

8. Cheretis C, Dietrich F, Chatzistamou I, Politi K, Angelidou E, Kiaris H, Mkrtchian S and Koutselini H: Expression of ERp29, an endoplasmic reticulum secretion factor in basal-cell carcinoma. Am J Dermatopathol 28: 410-412, 2006.

9. Zhang D and Putti TC: Over-expression of ERp29 attenuates doxorubicin-induced cell apoptosis through up-regulation of Hsp27 in breast cancer cells. Exp Cell Res 316: 3522-3531, 2010.

10. Yuan LW, Liu DC and Yang ZL: Correlation of S1P1 and ERp29 expression to progression, metastasis, and poor prognosis of gallbladder adenocarcinoma. Hepatobiliary Pancreat Dis Int 12: 189-195, 2013

11. Deng YJ, Tang N, Liu C, Zhang JY, An SL, Peng YL, Ma LL, Li GQ, Jiang Q, Hu CT, et al: CLIC4, ERp29, and Smac/DIABLO derived from metastatic cancer stem-like cells stratify prognostic risks of colorectal cancer. Clin Cancer Res 20: 3809-3817, 2014.

12. Qi L, Wu P, Zhang X, Qiu Y, Jiang W, Huang D, Liu Y, Tan P and Tian Y: Inhibiting ERp29 expression enhances radiosensitivity in human nasopharyngeal carcinoma cell lines. Med Oncol 29: 721-728, 2012.

13. Ye W, Zhang R, Hu Y, Xu X and Ying K: Increased expression of endoplasmic reticulum protein 29 in lung adenocarcinoma is associated with chemosensitivity to gemcitabine. Anticancer Drugs 26: 612-619, 2015.

14. Wu P, Zhang H, Qi L, Tang Q, Tang Y, Xie Z, Lv Y, Zhao S and Jiang W: Identification of ERp29 as a biomarker for predicting nasopharyngeal carcinoma response to radiotherapy. Oncol Rep 27: 987-994, 2012.

15. Schäfer C, Seeliger H, Bader DC, Assmann G, Buchner D, Guo Y, Ziesch A, Palagyi A, Ochs S, Laubender RP, et al: Heat shock protein 27 as a prognostic and predictive biomarker in pancreatic ductal adenocarcinoma. J Cell Mol Med 16: 1776-1791, 2012.
16. Guo Y, Ziesch A, Hocke S, Kampmann E, Ochs S, De Toni EN, Göke B and Gallmeier E: Overexpression of heat shock protein 27 (HSP27) increases gemcitabine sensitivity in pancreatic cancer cells through S-phase arrest and apoptosis. J Cell Mol Med 19: 340-350, 2015 .

17. Zhang YH, Belegu V, Zou Y, Wang F, Qian BJ, Liu R, Dai P, Zhao W, Gao FB, Wang L, et al: Endoplasmic reticulum protein 29 protects axotomized neurons from apoptosis and promotes neuronal regeneration associated with erk signal. Mol Neurobiol 52: 522-532, 2015.

18. Moysan E, Bastiat G and Benoit JP: Gemcitabine versus modified gemcitabine: A review of several promising chemical modifications. Mol Pharm 10: 430-444, 2013.

19. Zhou L, Qi L, Jiang L, Zhou P, Ma J, Xu X and Li P: Antitumor activity of gemcitabine can be potentiated in pancreatic cancer through modulation of TLR4/NF- $\kappa \mathrm{B}$ signaling by 6-shogaol. AAPS J 16: 246-257, 2014.

20. Pauwels B, Korst AE, Lardon F and Vermorken JB: Combined modality therapy of gemcitabine and radiation. Oncologist 10: 34-51, 2005.

21. Huang C, Wang JJ, Jing G, Li J, Jin C, Yu Q, Falkowski MW and Zhang SX: Erp29 attenuates cigarette smoke extract-induced endoplasmic reticulum stress and mitigates tight junction damage in retinal pigment epithelial cells. Invest Ophthalmol Vis Sci 56: 6196-6207, 2015

22. Liu R, Zhao W, Zhao Q, Liu SJ, Liu J, He M, Xu Y, Wang W, Liu W, Xia QJ, et al: Endoplasmic reticulum protein 29 protects cortical neurons from apoptosis and promoting corticospinal tract regeneration to improve neural behavior via caspase and erk signal in rats with spinal cord transection. Mol Neurobiol 50: 1035-1048, 2014.

23. Morgan MA, Parsels LA, Parsels JD, Mesiwala AK, Maybaum J and Lawrence TS: Role of checkpoint kinase 1 in preventing premature mitosis in response to gemcitabine. Cancer Res 65 : 6835-6842, 2005.

24. Luk PP, Galettis P and Links M: ERK phosphorylation predicts synergism between gemcitabine and the epidermal growth factor receptor inhibitor AG1478. Lung Cancer 73: 274-282, 2011.

25. Calderwood SK and Gong J: Heat shock proteins promote cancer: It's a protection racket. Trends Biochem Sci 41: 311-323, 2016.

26. Taylor RP and Benjamin IJ: Small heat shock proteins: A new classification scheme in mammals. J Mol Cell Cardio 38: 433-444, 2005.

27. Nakashima M, Adachi S, Yasuda I, Yamauchi T, Kawaguchi J, Itani M, Yoshioka T, Matsushima-Nishiwaki R, Hirose Y, Kozawa O, et al: Phosphorylation status of heat shock protein 27 plays a key role in gemcitabine-induced apoptosis of pancreatic cancer cells. Cancer Lett 313: 218-225, 2011.

28. Zoubeidi A and Gleave M: Small heat shock proteins in cancer therapy and prognosis. Int J Biochem Cell Bio 44: 1646-1656, 2012.

29. Kostenko S and Moens U: Heat shock protein 27 phosphorylation: Kinases, phosphatases, functions and pathology. Cell Mol Life Sci 66: 3289-3307, 2009

30. Köpper F, Bierwirth C, Schön M, Kunze M, Elvers I, Kranz D, Saini P,Menon MB, WalterD, Sørensen CS, etal:Damage-induced DNA replication stalling relies on MAPK-activated protein kinase 2 activity. Proc Natl Acad Sci USA 110: 16856-16861, 2013.

31. Evans J, Ko Y, Mata W, Saquib M, Eldridge J, Cohen-Gadol A, Leaver HA, Wang S and Rizzo MT: Arachidonic acid induces brain endothelial cell apoptosis via p38-MAPK and intracellular calcium signaling. Microvasc Res 98: 145-158, 2015.

32. Kim J, Jung H, Lim W, Kim S, Ko Y, Karna S, Kim O, Choi Y, Choi $\mathrm{H}$ and Kim O: Down-regulation of heat-shock protein 27-induced resistance to photodynamic therapy in oral cancer cells. J Oral Pathol Med 42: 9-16, 2013.

33. Liu Z, Li D, Zheng X, Wang E and Wang J: Selective induction of apoptosis: Promising therapy in pancreatic cancer. Curr Pharm Des 19: 2259-2268, 2013. 